\title{
Student generated digital media and community-based learning within a COVID-19 induced landscape: Lessons from the field
}

\author{
Nerhene Davis'*, Victoria Rautenbach \\ ${ }^{a}$ Department of Geography, Geoinformatics and Meteorology, University of Pretoria, Pretoria, South Africa, (nerhene.davis, \\ victoria.rautenbach)@up.ac.za \\ * Corresponding author
}

Keywords: South Africa, Geography, Geoinformatics, digital media, community engagement, spatial citizenship

\begin{abstract}
:
Uncertainty caused by the COVID-19 pandemic prompted a radical transformation of teaching and learning approaches on all levels of education across the globe (Mishra et al, 2020). In South Africa, the strategy adopted by higher education institutions were labelled as an 'emergency response teaching and online learning approach' (Williams, 2020; Nworie, 2021). The introduction of a new module within this recalibrated context thus heightened the sense of urgency for my colleague and I to critically engage with online learning outcomes, capacities, and assessment tools. Two key realisations informed our deliberations about teaching the new module during this time. In the first instance, we realized that our approach to teaching and assessment should not only require the mastering of requisite subject relevant knowledge, but our students (with vastly different digital literacy levels) would need to convincingly demonstrate their learning and communication skills in a redefined digital space. Secondly, we wanted the subject knowledge that we were teaching the students to transcend academic boundaries through demonstrative practical application and beneficial value for the communities they encounter. These imperatives encouraged us to actively explore the use of community engagement to introduce data capturing, management, and visualization to students in the new geography module at our university. With this intended vision in our minds, we decided to combine learning in two modules into one assessment exercise. Students enrolled for the new third year Geography module were subdivided into groups with third year Geoinformatics students to produce a digital media product about a real-world problem with a defined spatial dimension. To this end, students were therefore required to capture dynamics related to access to health care facilities in the city from a local community perspective. The assignment required the Geography students to capture perspectives about access to health care facilities from different community vantage points using digital platforms to engage and learn from community members. The geoinformatics students were required to produce maps and visualisations of the data about the area that could be given to the community leaders to help them engage with local government or plan insitu upgrades for the area.
\end{abstract}

With this experiential approach to learning, which combines a level of community-based engagement with the academic process we were therefore aspiring to encourage a level of engaged citizenship that would not only foster learning retention and success (Strait, Turk, and Nordyke, 2015) but also translate into improved problem-solving skills to the benefit of local communities. For Rock (2021), when community-based learning and engagement is centred on the relational concept of space, the development of spatial citizenship would provide tangible benefits for community partners as well as students. It was therefore important for us that the final products produced for this joint assessment; the Student Generated Digital media (SDGM) in the form of story maps, short films, or blogs; demonstrated not only the requisite subject knowledge the students should have acquired, but also the beneficial relevance of community engagement from a pedagogical perspective.

SGDM as an assessment tool has been identified as a valuable approach for the assessment of learning of students within diverse contexts (Kemp et al, 2012; Hill et al, 2018). Various studies have already reported higher levels of student engagement and improved learning performance where these SDGM assessments tools have been applied in tandem with community-based learning strategies (Vogler et al, 2012). Despite reports of successes with these approaches, the research conducted for this paper was concerned with gauging the outcomes of our experiential approach in a redefined learning landscape. In this paper we therefore capture the nature and extent of challenges encountered in terms of the student support that were required within the predominantly online learning context; we also interrogate the suitability of our marking rubrics and reflect on the scalability of the approach we used based on our 
own experiences and tutor questionnaire feedback. The digital artefacts were also used to qualitatively assess the depth/level of students learning and their critical engagement with the content. Finally, the assessment methodologies (e.g., marking rubric and instructional design) were critically reviewed against student questionnaire feedback and other criterion to weigh its pedagogical, instructional, and curricular relevance. Finally, findings from the analysis conducted during this inquiry would be used to develop a methodology for SGDM as an assessment tool for a geoscience module in the South African context.

\section{References}

Hill, J., Walkington, H. \& King, H. 2018. Geographers and the scholarship of teaching and learning, Journal of Geography in Higher Education, 42:4, 557-572, DOI:

10.1080/03098265.2018.1515188.

Kemp, J., Mellor, A, Kotter, R. \& Oosthoek, J.W. 2012. Student-Produced Podcasts as an Assessment Tool: An Example from Geomorphology. Journal of Geography in Higher Education, Vol. 36, No. 1, 117-130, February 2012

Mishra,L., Gupta,T.; Shree,A. 2020. Online teaching-learning in higher education during lockdown period of COVID19 pandemic, International Journal of Educational Research, Volume 1, https://doi.org/10.1016/j.ijedro.2020.100012.

Nworie, J. 2021. Beyond COVID-19: What's Next for Online Teaching and Learning in Higher Education? EDUCAUSE REVIEW, 21 May 2021.

Rock, A.E. 2021. Bringing geography to the community: community-based learning and the geography classroom. GeoJournal (2021).

Strait, J., Turk, J., \& Nordyke, K. J. (2015). Pedagogy of civic engagement, high-impact practices, and e-service- L earning. In J. R. Strait \& K. Nordyke (Eds.), EServicelearning creating experiential learning and civic engagement through online and hybrid courses (pp. 7-19). Stylus Publishing.

Vogler, R., Hennig, S., Jekel, T., \& Donert, K. (2012). Towards a Concept of 'Spatially Enabled Learning.' In T. Jekel, A. Car, J. Strobl, \& G. Griesebner (Eds.), GI_Forum 2012: Geovisualization, Society and Learning (pp. 204-211). WichmannVerlag.

Williams A.J., 2020 "Did the Scramble to Remote Learning Work? Here's What Higher Ed Thinks," Chronicle of Higher Education, June 8, 2020. 